\title{
Exploitation potential of groundwater in Yangzhuang Basin, China under recharge enhancement
}

\author{
Xiaogang $\mathrm{Fu}^{1,2,3,4^{*}}$, Zhonghua Tang ${ }^{1}$, WenBin $\mathrm{Lv}^{5}$, Xiaoming Wang ${ }^{2}$, Baizhong Yan ${ }^{2,3,4}$ \\ ${ }^{1}$ School of Environmental Studies, China University of Geoscience, Wuhan 430074, China \\ ${ }^{2}$ Hebei GEO University, Shijiazhuang 050031, China \\ ${ }^{3}$ Key Laboratory of Sustained Development and Utilization of Water Resources, Hebei Province, Shijiazhuang 050031, China \\ ${ }^{4}$ Hebei Province Collaborative Innovation Center for Sustainable Utilization of Water Resources and Optimization of Industrial \\ Structure, Shijiazhuang 050031, China \\ ${ }^{5}$ Third Hydrogeological Engineering Team of Hebei Provincial Geological and Mining Burea, Hengshui 053099, China
}

Corresponding Author Email: fuxiaogang@hgu.edu.cn

https://doi.org/10.18280/ijht.360213

Received: 1 September 2017

Accepted: 2 February 2018

\section{Keywords:}

Yangzhuang basin, karst groundwater

system, recharge enhancement,

numerical simulation, exploitation

potential

\begin{abstract}
This paper aims to determine the exploitation potential of groundwater and the optimal exploitation plan in karst areas. Considering the hydrogeological and boundary conditions of Yangzhuang karst groundwater system, a generalized hydrogeological model of groundwater flow was created and the governing equations were derived for karst groundwater simulation in the study area. Then, the study area was divided into 31,152 rectangular grids by finite difference method. The established model was applied to simulate the groundwater levels in 25 observation wells, and proved to be feasible through the fitting of simulated results with the measured results. Next, several forecast conditions and constraints were laid down, including but not limited to the precipitation calculated by historical series and future series (nonstationary) and the recharge enhancement measures like greening and retaining dam construction. Based on these conditions and constraints, a forecast model was created on Visual MODFLOW and coupled with the established hydrogeological model using the groundwater management (GWM) process to evaluate the maximum exploitation potential of groundwater in the study area, and determine the optimal exploitation plan for all groundwater source fields after implementing the above recharge enhancement measures. The evaluation results show that the exploitation volume calculated by the non-stationary future precipitation series outperforms that by the historical precipitation series in prediction accuracy; the allowable exploitation volume should be determined as $258,000 \mathrm{~m}^{3} / \mathrm{d}$; by the most conservative estimate, the groundwater exploitation volume of the groundwater source fields can be maximized at $243,500 \mathrm{~m}^{3} / \mathrm{d}$. The research findings lay the basis for sustainable exploitation and utilization of karst groundwater in the study area and similar regions.
\end{abstract}

\section{INTRODUCTION}

Karst aquifers are the most productive groundwater supplies on Earth, providing 20 25\% of drinking water to the global population. The karst groundwater plays an essential role in global water cycle [1-5]. China has a larger karst area than any other country in the world. Almost $1 / 3$ of its territory $\left(3.46 \times 10^{6} \mathrm{~km}^{2}\right)$ belongs to the karst area, about $15.73 \%$ of the global carbonatite outcrop area $\left(2.2 \times 10^{7} \mathrm{~km}^{2}\right)$. The karst groundwater storage accounts for $23 \%$ of the total groundwater reserve in the country.

The wealth of karst groundwater is a mixed blessing to China. The intense exploitation and utilization of karst groundwater in recent decades have, on the one hand, promoted regional socioeconomic development, and, on the other hand, posed adverse impacts on the eco-environment, such as groundwater recession, dry-up of karst springs and karst subsidence [6-13]. This calls for accurate evaluation of the exploitation potential of karst systems. However, it is rather difficult to determine the exact potential or the optimal plan, as karst aquifers are often heterogenous and the runoffs switch repeatedly between the surface and the underground.

With the rapid development of mathematical and computer technologies, numerous new theories and methods have been applied to evaluate the exploitation potential of karst groundwater, namely, artificial neural networks (ANNs), time series methods, analytic hierarchy process (AHP), system analysis methods and geographic information system (GIS). Meanwhile, many quantitative evaluation approaches have emerged, whose accuracy depends on the precise measurement of aquifer parameters through geological monitoring. Based on geological conditions, the mathematical and computer techniques are often adopted to enhance the evaluation accuracy of karst groundwater exploitation potential.

Focusing on the high heterogeneity of karst aquifers, the equivalent porous media (EPM) is one of the simplest yet most debated strategies to characterize karst groundwater systems. In the EPM, a karst aquifer is assumed as a porous medium with karst channels and large faults being areas of high hydraulic conductivity [14-15]. The representative elementary volume (REV) can be introduced if the area of interest is large enough for the EPM [16-17]. Despite the low accuracy on the local scale, the EPM can accurately simulate the groundwater flow processes (e.g. hydraulic heads, volumetric flow and general flow directions) of complex aquifers on the regional 
and medium scales [18]. Therefore, the EPM has been extensively employed for numerical simulation of karst areas [19-22].

The karst groundwater system in Yangzhuang Basin lies in south China's Shandong Province. With a narrow exit, it is a typical closed groundwater system with excellent conductivity and regulation effect. The hydrodynamic field is basically uniform, and the groundwater is mainly drained through springs. At present, the groundwater resources in the basin are being explored extensively. Several medium-scale groundwater source fields have been established, including Houshiwan, Xishilou, Weizhuang and Yangzhuang. The exploitation of these fields has boosted the regional economy and living standard, but negatively affected the ecoenvironment. Suffice it to say that Yangzhuang karst groundwater system is the very representative of karst areas in northern China.

In northern China, the karst areas are not well developed or heterogeneously distributed. The motion of karst groundwater is dominated by laminar flow and subjected to Darcy's law. Well-developed karst caves are only seen in local areas, where the karst groundwater moves as a non-Darcy flow. Considering the hydrogeological and boundary conditions of Yangzhuang karst groundwater system, this paper creates a generalized hydrogeological model of groundwater flow and derives the governing equations for karst groundwater simulation in the study area. Then, the study area was divided into 31,152 rectangular grids by finite difference method. The established model was applied to simulate the groundwater levels in 25 observation wells, and proved to be feasible through the fitting of simulated results with the measured results. Next, several forecast conditions and constraints were laid down, including but not limited to the precipitation calculated by historical series and future series (non-stationary) and the recharge enhancement measures like greening and retaining dam construction. Based on these conditions and constraints, a forecast model was created on Visual MODFLOW (VM) [23] and coupled with the established hydrogeological model using the groundwater management (GWM) process to evaluate the maximum exploitation potential of groundwater in the study area, and determine the optimal exploitation plan for all groundwater source fields after implementing the above recharge enhancement measures [24]. The research findings lay the basis for sustainable exploitation and utilization of karst groundwater in the study area and similar regions.

\section{STUDY AREA}

\subsection{Hydrogeological conditions}

Yangzhuang Basin is a $650 \mathrm{~km}^{2}$ synclinal basin amidst mountains in northern China's Shandong Province. The elevation of the basin ranges from $50 \mathrm{~m}$ to $600 \mathrm{~m}$ [25]. The local strata, dominated by carbonatites, are inclined towards the centre of the basin. In the northwest, north and east of the basin, there exist surface watersheds of Cambrian limestones, metamorphic rocks and magmatic rocks. The southern and southwestern strata are in contact with the coal-bearing strata formed in Zaozhuang and Huashigou faults. The hydrogeological map of Yangzhuang Basin is presented in Figure 1.
As a typical closed karst groundwater reservoir, the basin mainly relies on precipitation for groundwater recharge. In general, the groundwater flows from the northeast towards the southwest, and leaves the basin through a group of springs. The Xinxue River is the only surface river in the basin. The river cuts deep into the ground. Many of its segments are drained and recharged together with groundwater. Thus, the river becomes the major channel for groundwater recharge and discharge. Moreover, a 15.4km-long, 375 1,500m-wide Quaternary paleochannel is situated in the central part of the basin. Since the sand gravel layer directly covers the underlying limestone aquifer, the karst groundwater can also be discharged into pore water and flow outside the basin.

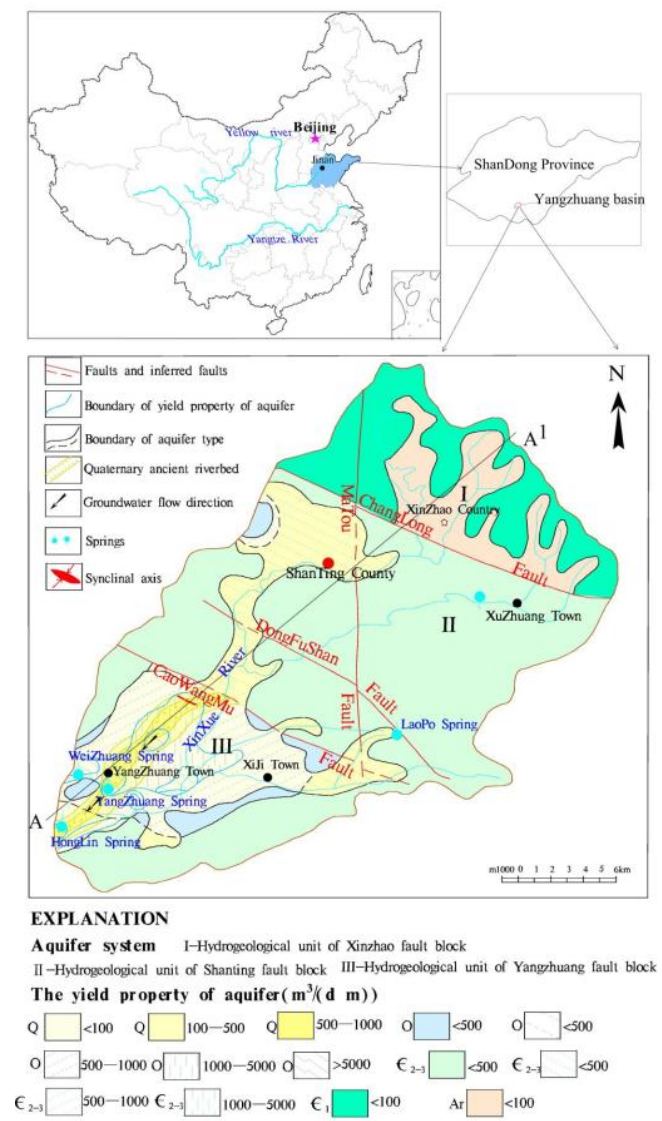

(a) Partition of hydrogeological units of Yangzhuang basin

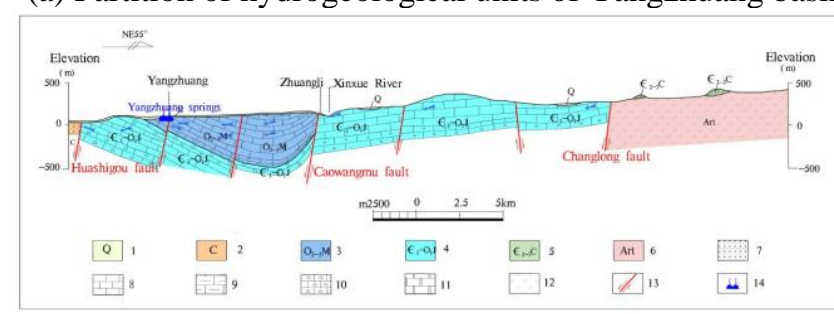

1-Quaternary; 2-Carboniferous; 3-Majiagou formation;

4-Jiulongshan formation; 5-Changqing Group; 6- magmatic rock; 7Sandstone; 8-Limestone; 9-Marlstone; 10-Oolitic limestone; $11-$ Dolomite; 12-Granite; 13-Fault; 14-Spring groups

(b) Hydrogeological cross-section of Yangzhuang Basin(NE$\mathrm{SW})$

Figure 1. Hydrogeological map of Yangzhuang Basin

As shown in Figure 1(a), Yangzhuang Basin is divided by Changlong and Caowangmu faults into three hydrogeological units, namely, Xinzhao, Shanting and Yangzhuang blocks. The three units differ greatly from each other in hydrogeological conditions. Xinzhao and Shanting blocks 
belong to the middle and upper reaches of the Xinxue River, while Yangzhuang Block lies in the lower reaches of the river. Hence, Yangzhuang block outperforms the former two blocks in groundwater circulation and acquifer yield. Most of the karst groundwater in Yangzhuang Basin is stored in Yangzhuang block.

\subsection{Boundary conditions}

Yangzhuang Basin boasts a closed karst groundwater system with complete recharge, run-off and discharge conditions. The syncline structure of the groundwater system is consistent with the landform of the basin. The north-western and eastern boundaries consist of impermeable metamorphic rocks of Taishan group and mid-lower Cambrian shales, interbedded with limestones. The southern boundary is impermeable, as it is connected to the coal-bearing strata formed in Zaozhuang and Huashigou faults. There is a narrow, low profile between Sanshantou and Longshantou, which serves as the only outlet of surface water and groundwater of the entire basin.

(1) Lateral boundaries: The karst groundwater system was simulated using the natural boundaries of the basin, aiming to prevent the computing load resulted from artificial boundaries. The lateral boundaries on the plane of the study area are impermeable except the groundwater outlet between Sanshantou and Longshantou.

(2) Bottom boundary: The drilling data shows that the karst groundwater concentrate above the depth of $220 \mathrm{~m}$. Below that depth, the karst system is poorly developed. Hence, the bottom boundary was generalized as an impermeable boundary with the elevation of $150 \mathrm{~m}$ (buried depth: $220 \mathrm{~m}$ ).

(3) Top boundary: The top boundary of the karst groundwater system is the gas-soil interface. The unsaturated zone from ground to water table is the bond for connecting precipitation, surface water and groundwater. The karst groundwater system is discharged and recharged through the top boundary through discharge/recharge of Xinxue River system, the return water of irrigation, the infiltration recharge of precipitation and evaporation/evapotranspiration.

\section{MODELLING AND SIMULATION}

\subsection{Generalized hydrogeological model}

Based on the hydrogeological and boundary conditions, a generalized hydrogeological model was established for the karst groundwater system in the study area considering the four discharge and recharge modes: the discharge/recharge of Xinxue River system, the return water of irrigation, the infiltration recharge of precipitation and evaporation/evapotranspiration.

The discharge/recharge of Xinxue River was generalized as a linear quantitative discharge/recharge term changing with time and space according to the distribution of Xinxue River system and its tributaries.

The return water of irrigation was generalized as a seasonal, local planar recharge term according to the plant area of crops, the irrigation system, the total amount of irrigation water and the return flow coefficient of irrigation water in the study area.

The infiltration recharge of precipitation was generalized as follows. The mean precipitation infiltration coefficients of different zones were calculated according to relevant data and factors (e.g. lithology, terrain, vegetation and groundwater level); then, the infiltration recharge of precipitation was computed based on the aerated area, precipitation and mean precipitation infiltration coefficient of each zone. In the basin, the area from the periphery of the centre to the north of Caowangmu fault is the primary recharge zone of karst groundwater, while the area between the centre and the valleys is another important recharge zone.

The evaporation capacity is mainly related to depth of groundwater, lithology of aeration zone, local vegetation, climate and it is known from the experimental results of karst groundwater comprehensive experimental field in Yangzhuang basin that the zones where groundwater is deeper than $4 \mathrm{~m}$ shows low evaporation from phreatic water. Now the groundwater in Yangzhuang basin was deeper than $4 \mathrm{~m}$ except in the areas near Weizhuang spring group and the exit of the basin, indicating that there is only an extremely weak evaporation loss of karst groundwater near the spring group and basin outlet throughout the basin, so the evaporation/evapotranspiration was ignored in the subsequent simulation and analysis,

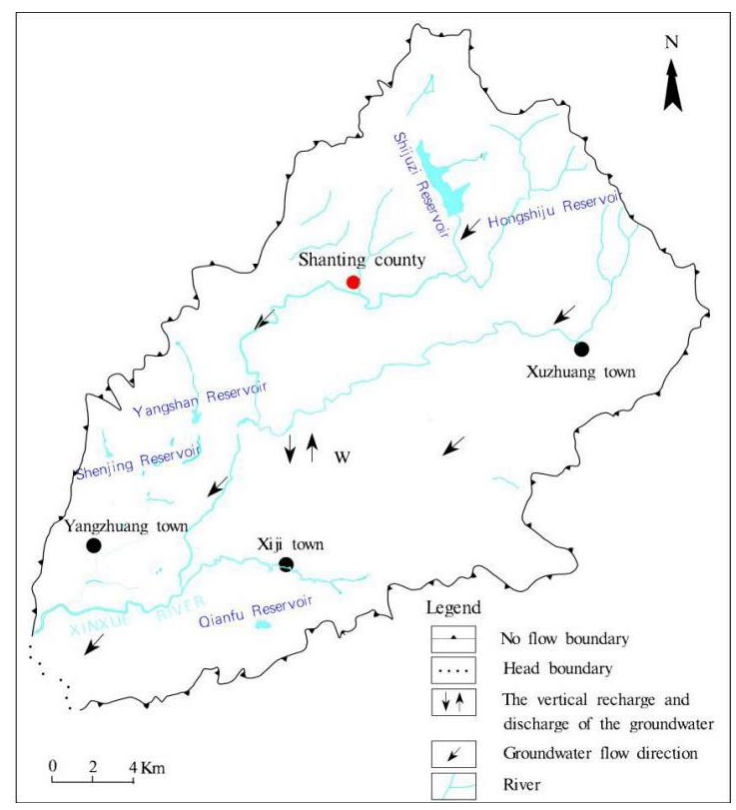

Figure 2. Generalized hydrogeological model

\subsection{Governing equations}

Based on the generalized model, the governing equations for karst groundwater simulation in Yangzhuang Basin can be expressed as [26]:

$$
\left\{\begin{array}{l}
\frac{\partial}{\partial x}\left\{K[H-Z(x, y)] \frac{\partial H}{\partial x}\right\}+\frac{\partial}{\partial y}\left\{K[H-Z(x, y)] \frac{\partial H}{\partial y}\right\}-\varepsilon=u \frac{\partial H}{\partial t} \quad(x, y) \in \Omega, t>0 ; \\
\left.H(x, y, t)\right|_{t=0}=H_{0}(x, y) \quad(x, y) \in \Omega, t=0 ; \\
\left.K_{n} \frac{\partial H}{\partial n}\right|_{\Gamma_{2}}=0 \quad t>0 ; \\
\left.K_{n^{\prime}}(H-z) \frac{\partial H}{\partial n^{\prime}}\right|_{\Gamma_{r^{\prime}}}=q_{L}(x, y, t) \quad t>0 ; \\
\left.Q_{\mathrm{r}}(x, y, t)\right|_{\Gamma_{3}}=C_{r}(x, y) \times\left\{H(x, y, t)-H_{r}(x, y, t)\right\} \quad t>0 ;
\end{array}\right.
$$

where $\Omega$ is the study are; $\mathrm{H}_{0}(\mathrm{x}, \mathrm{y})$ and $\mathrm{H}(\mathrm{x}, \mathrm{y})$ are the initial hydraulic head and the hydraulic head, respectively $(\mathrm{m})$; $\mathrm{K}$ is horizontal hydraulic conductivity $(\mathrm{m} / \mathrm{d}) ; \varepsilon$ is the source-to-sink 
factor of groundwater $(\mathrm{m} / \mathrm{d}) ; \Gamma_{1}$ is the impermeable boundary; $\Gamma_{2}{ }^{1}$ is the Neumann boundary; $\mathrm{u}$ is the specific yield; $\mathrm{Z}(\mathrm{x}, \mathrm{y})$ is the aquifer floor elevation $(\mathrm{m}) ; \mathrm{q}_{\mathrm{L}}(\mathrm{x}, \mathrm{y})$ is the recharge per unit width $(\mathrm{m} / \mathrm{d})$ of Neumann boundary; $\mathrm{H}_{\mathrm{r}}(\mathrm{x}, \mathrm{y}, \mathrm{t})$ is the water level of Xinxue River.

\subsection{Grid meshing}

Pore water and karst groundwater are two main types of groundwater in the study area. The two types of groundwater enjoy close hydraulic connections, thanks to the lack of aquiclude in between. Thus, the groundwater in the study area can be viewed as one layer, and treated as a 2D planar, isotropic flow. Vertically speaking, the hydraulic connections are even closer in local areas. Besides, the perennial data on groundwater dynamics are not detected layer by layer, making it impossible to verify the vertical distribution of water pressure. Therefore, different layers were assumed to have the same hydraulic features, and the two types of groundwater were considered to share the same hydrogeological parameters and a uniform flow field.

The primary causes of groundwater discharge are artificial exploitation and spring discharge. The artificial exploitation mainly serves urban and industrial consumptions, irrigation demands, and stock farming requirements. Relevant statistics on 2013 2016 show that the exploitation volume of karst groundwater averages at $1.708 \times 10^{5} \mathrm{~m}^{3} / \mathrm{d}$. In addition to the wells in groundwater source fields, there are many exploiting wells scattered across the basin. In this case, it is impossible the identify the location or exploitation volume of each scattered well. Hence, all the scattered wells were deemed as planar wells, and the artificial exploitation was treated as planar discharge. The data on spring discharge were available at the hydrometric station near Weizhuang spring group. Through a water balance test at the station, it is learned that the springs only flew in two periods: July-October 2013 and August-September 2016. The mean flow of the springs was $437 \mathrm{~m}^{3} / \mathrm{d}$.

Considering the above, a difference equation was established directly from Darcy's law and water balance principle, and the $650 \mathrm{~km}^{2}$ study area was meshed into 31,152 rectangular grids by finite difference method. The grids fall into 177 rows and 176 columns in a plane. Overall, there are 16,447 active grids and 14,705 inactive grids. The calculation nodes are located at the centres of the grids [27].

\subsection{Numerical simulation}

The model is tested by taking the dynamic change of groundwater levels in 25 observation wells. According to the data collected from "Exploration report of xiji groundwater area in zaozhuang city, shandong province" and "The 1:50,000 hydrogeological survey report in Yangzhuang basin" (e.g. exploitation volume, precipitation intensity and variation in groundwater level), the simulation was carried out for 41 months from May 26th, 2013 through September 26th, 2016. The data acquired between May 26th, 2013 and January 6th, 2015 were adopted for model correction, while those between January 7th, 2015 to September 26th, 2016 were selected for model testing.

Inspired by Reference [28], the study area was divided into 19 hydraulic parameter zones and 8 precipitation infiltration zones (Figures 4-5), each of which has the same hydrogeological parameters (Tables 1-2). These parameters were initialized based on local conditions and pumping test results. The initial values were used to calibrate the established hydrogeological model. Then, the model was applied to simulate the groundwater levels, and the simulated results were modified to fit the measured values in the 25 observation wells [29]. The fitting curves between the simulated and measured results are shown in Figure 3 below.

As shown in Figure 3, over $80 \%$ of all observation wells had a relative fitting error below $5 \%$, and the simulated results agreed well with the trend of the observed groundwater level. Therefore, the established model can reflect the dynamic changes of groundwater level in the study area. Next, this model was applied to forecast the dynamic changes of groundwater level under different exploitation conditions.

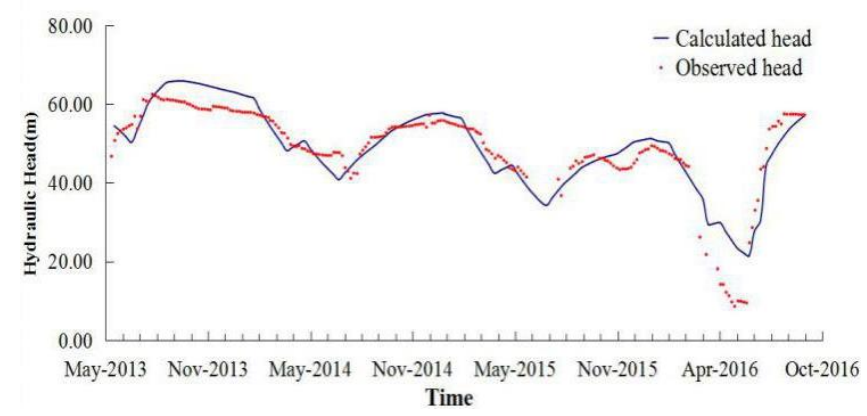

(a) The observation well of HouShiWan

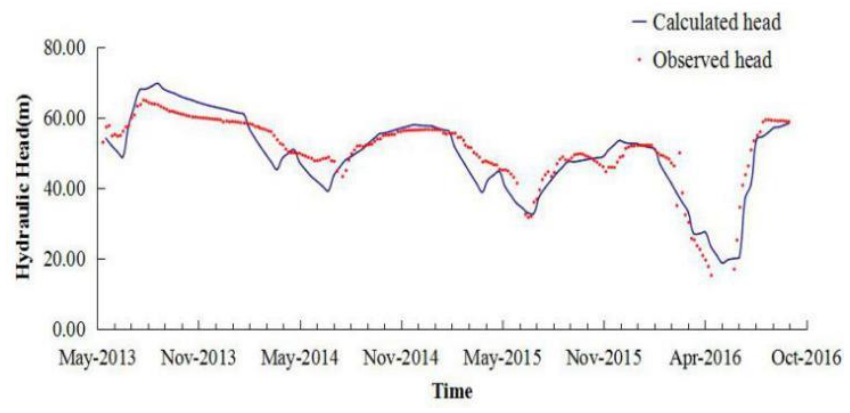

(b) The observation well of WangHang

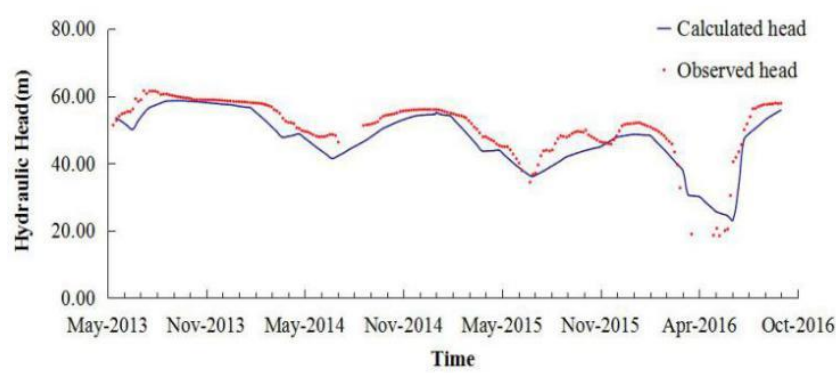

(c) The observation well of Dongyu

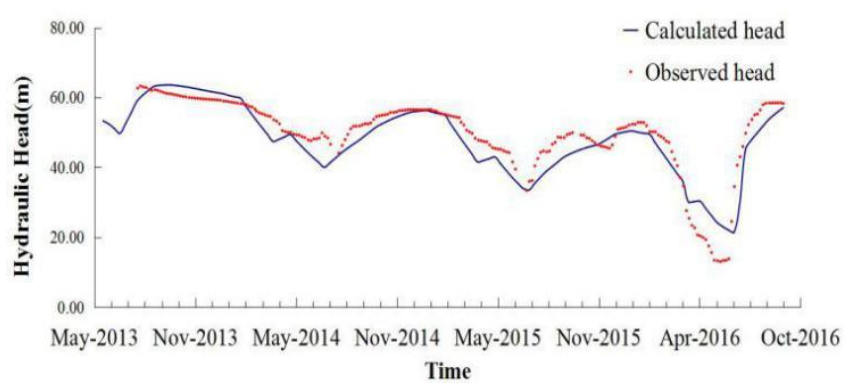

(d) The observation well of Dutun

Figure 3. Fitting curves of groundwater levels in typical observation wells 


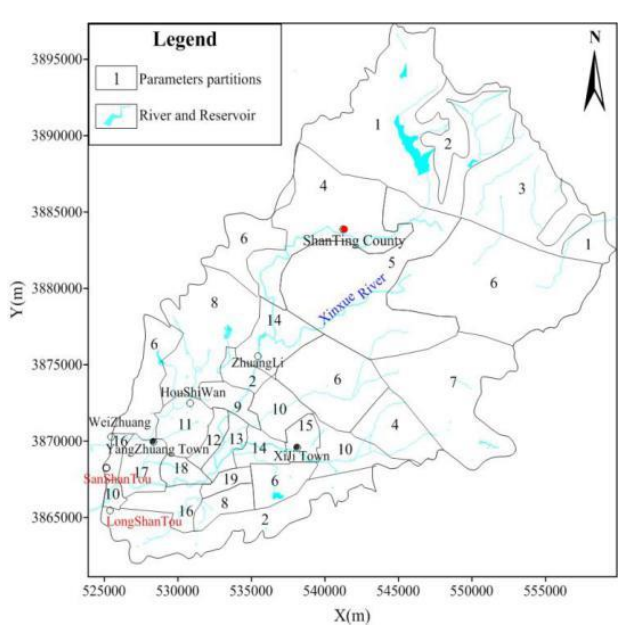

Figure 4. Hydraulic parameter zones

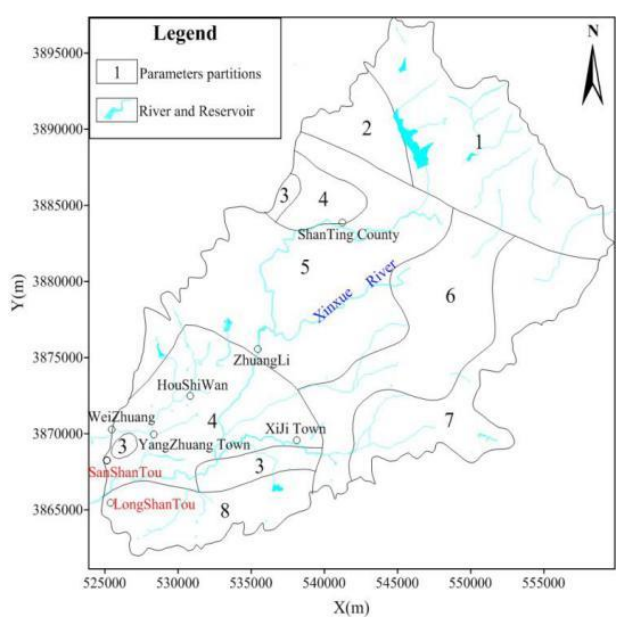

Figure 5. Precipitation infiltration zones

Table 1. Precipitation infiltration coefficients

\begin{tabular}{c|cccc}
\hline Zone Number & 1 & 2 & 3 & 4 \\
\hline Value & 0.069 & 0.184 & 0.188 & 0.139 \\
\hline Zone Number & 5 & 6 & 7 & 8 \\
\hline Value & 0.195 & 0.192 & 0.100 & 0.206 \\
\hline
\end{tabular}

Table 2. Hydrogeological parameters

\begin{tabular}{ccc}
\hline $\begin{array}{c}\text { Zone } \\
\text { Number }\end{array}$ & $\begin{array}{c}\text { Hydraulic } \\
\text { Conductivity }(\mathbf{K})(\mathbf{m} / \mathbf{d})\end{array}$ & $\begin{array}{c}\text { Specific } \\
\text { Yield }(\boldsymbol{\mu})\end{array}$ \\
\hline 1 & 1.5 & 0.005 \\
\hline 2 & 4 & 0.011 \\
\hline 3 & 1.1 & 0.002 \\
\hline 4 & 5.6 & 0.019 \\
\hline 5 & 2.5 & 0.004 \\
\hline 6 & 3.2 & 0.011 \\
\hline 7 & 1 & 0.004 \\
\hline 8 & 3 & 0.010 \\
\hline 9 & 80 & 0.06 \\
\hline 10 & 25 & 0.004 \\
\hline 11 & 200 & 0.036 \\
\hline 12 & 250 & 0.04 \\
\hline 13 & 24 & 0.004 \\
\hline 14 & 5 & 0.012 \\
\hline 15 & 7 & 0.009 \\
\hline 16 & 50 & 0.04 \\
\hline 17 & 80 & 0.06 \\
\hline 18 & 60 & 0.04 \\
\hline 19 & 3.5 & 0.015 \\
\hline
\end{tabular}

\section{FORECAST CONDITIONS}

\subsection{Precipitation}

As the ultimate source of karst water, the precipitation is crucial to the forecast of groundwater level. However, the current meteorological and hydrological methods are unable to predict the precipitation in the long run. The only way is to construct a precipitation series based on certain rules and use it as the condition of the forecast model. Here, the future precipitation is determined in the following steps.

(1) Historical precipitation series

The perennial mean precipitation series and historical precipitation series are commonly used in precipitation analysis. The former helps to forecast the overall trend of groundwater level, while the latter tests the aquifer's regulation capacity and the effect of precipitation abundance on groundwater level. In our research, the historical precipitation series is selected for simulation, with the aim to test the regulation ability, storage capacity and recharge potential of aquifer. The simulation results were reasonable from the perspective of water supply safety.

Based on the series data on monthly precipitation in the study area from 1952 to 2016 , the cumulative percentage frequency analysis was carried out. The results (Figure 6) show that the annual precipitations were 880.96, 743.968 and $628.702 \mathrm{~mm}$ at the cumulative percentage frequencies of $\mathrm{P}=25 \%, \mathrm{P}=50 \%$ and $\mathrm{P}=75 \%$, respectively. These results correspond to typical years of 1963, 1972 and 1982.

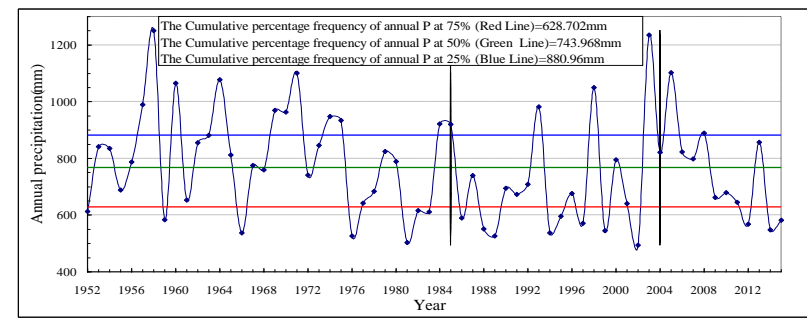

Figure 6. Duration curves and cumulative percentage frequency distribution of precipitation

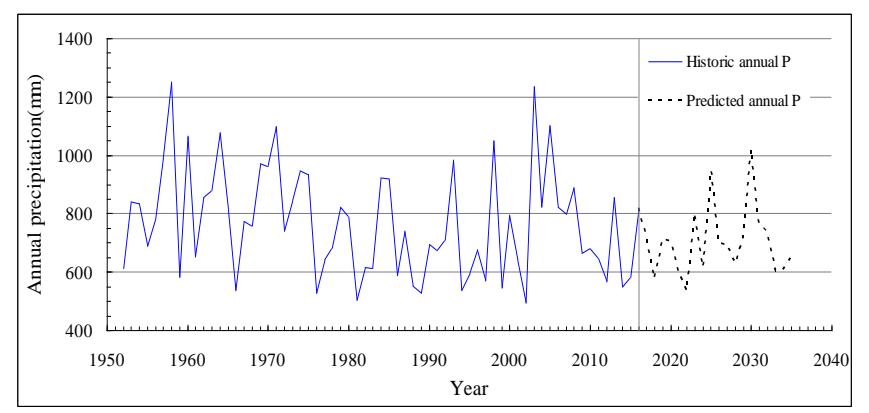

Figure 7. Historical annual precipitation curve and forecasted annual precipitation curve in the next 20 years

The continuous 20-year series (1985 2004) with the worst water supply condition (mean annual precipitation: $717.535 \mathrm{~mm} / \mathrm{a}$ ) was selected from the 64 -year precipitation data to serve as the historical hydrological series for forecast. The selected series covers the driest years and longest drought period in history, and can thus reflect the regulation capacity of aquifer in dry period.

(2) Future precipitation series 
The time series of annual precipitation can be regarded as a 1D nonstationary time series, consisting of a constant term that reflects its time-varying pattern and a random term with the mean of zero. The constant term can be approximated by functions and the random term can be fitted by linear models. The time series can be expressed as [30]:

$P(t)=T(t)+Z(t)+R(t)$

where $\mathrm{T}(\mathrm{t})$ is the change trend of precipitation; $\mathrm{Z}(\mathrm{t})$ is the periodic change of precipitation; $\mathrm{R}(\mathrm{t})$ is the random term. The sum of $\mathrm{T}(\mathrm{t})$ and $\mathrm{Z}(\mathrm{t})$ reflect the constant term of the time series. The random term equals the residual series after eliminating the constant term, which is normally considered as a nonstationary series.

Taking the said 64-year precipitation data as the fitting data, the $\mathrm{T}(\mathrm{t})$ and $\mathrm{Z}(\mathrm{t})$ were solved by stepwise regression and spectral analysis, respectively; $\mathrm{R}(\mathrm{t})$ was fitted by autoregression and used to predict the precipitations in the next 20 years. According to Figure 7 and Table 3, the mean precipitation was estimated as $707.74 \mathrm{~mm} / \mathrm{a}$, which signifies a relatively dry precipitation series.

Table 3. Precipitation forecasted based on non-stationary time series

\begin{tabular}{c|ccccc}
\hline Year & 2016 & 2017 & 2018 & 2019 & 2020 \\
\hline Annual precipitation (mm) & 819.47 & 721.29 & 577.07 & 714.20 & 704.48 \\
\hline Year & 2021 & 2022 & 2023 & 2024 & 2025 \\
\hline Annual precipitation (mm) & 599.34 & 534.84 & 802.50 & 617.02 & 947.45 \\
\hline Year & 2026 & 2027 & 2028 & 2029 & 2030 \\
\hline Annual precipitation $(\mathbf{m m})$ & 699.19 & 695.33 & 627.22 & 719.14 & 1019.40 \\
\hline Year & 2031 & 2032 & 2033 & 2034 & 2035 \\
\hline Annual precipitation $(\mathbf{m m})$ & 761.61 & 734.42 & 605.09 & 605.50 & 650.15 \\
\hline
\end{tabular}

\subsection{Constraints}

\section{(1) Karst collapse}

Karst collapse is a major geological disaster associated with the irrational exploitation of groundwater. The maximum exploitation depths of the groundwater source fields must be limited to reduce or eliminate the occurrence of the disaster in the basin.

In 2015, the study area did not suffer from any karst collapse although the groundwater reached the lowest level in history due to the lack of precipitation. Therefore, the lowest groundwater level at the groundwater source fields in that year were taken as the maximum exploitation depths if they were below the top of karst aquifer; the elevation of the top of karst aquifer was adopted as the maximum exploitation depth is otherwise. The results are shown in Table 4.

Table 4. Maximum exploitation depths

\begin{tabular}{ccccc}
\hline Well fields & $\begin{array}{c}\text { Maximum } \\
\text { level } \\
\text { depths } \\
\text { (m) }\end{array}$ & $\begin{array}{c}\text { The top } \\
\text { of karst } \\
\text { aquifers } \\
(\mathbf{m})\end{array}$ & $\begin{array}{c}\text { Level } \\
\text { depths } \\
\text { constraint } \\
(\mathbf{m})\end{array}$ & $\begin{array}{c}\text { water } \\
\text { levels } \\
\text { constraint } \\
\text { (m) }\end{array}$ \\
\hline YangZhuang & 34.274 & 19.94 & 35 & 29.559 \\
\hline XiShiLou & 40.00 & 45 & 45 & 22.235 \\
\hline WeiZhuang & 31.35 & 27.5 & 30 & 31.434 \\
\hline HouShiWan & 44.36 & 18.3 & 45 & 28.76 \\
\hline NanZhuang & 13.06 & 82.37 & 60 & 64.972 \\
\hline DuanZhuang & 24.1 & $/$ & 50 & 93.187 \\
\hline DongYu & 34.16 & 26.46 & 26 & 38.328 \\
\hline LongShanTou & $/$ & 28.16 & 20 & 38.062 \\
\hline XuPo & 36 & 65.5 & 36 & 32.956 \\
\hline WangHang & $/$ & 17.2 & 35 & 32.372 \\
\hline
\end{tabular}

(2) Groundwater level

The groundwater level should not decline continuously under the exploitation state.

\subsection{Recharge enhancement}

The groundwater recharge of the study area can be artificially enhanced in two ways: promoting precipitation infiltration through greening projects and elevating river leakage with retaining dams.

(1) Precipitation infiltration

The 1985 1992 results of the water balance test show that the precipitations at Xuzhuang forestry centre $(58.7 \mathrm{~mm})$ and Weizhuang hydrometric station $(59.2 \mathrm{~mm})$ were higher than their adjacent regions thanks to their high vegetation coverage. In general, $1 \%$ increase in mean vegetation coverage can enhance the annual precipitation by $3 \mathrm{~mm}$.

According to the statistics of the local forestry department, about $30 \%$ of the study area is currently covered by vegetations. Various greening projects are underway to promote vegetation coverage and water conservation. As stated in the local plan for eco-environment construction (2010 2020), the vegetation coverage of the study area will reach $60 \%$ and the annual precipitation will increase by $90 \mathrm{~mm}$. Thus, the attainable increment of precipitation infiltration was calculated based on the vegetation coverage of $60 \%$ and the annual precipitation increment of $90 \mathrm{~mm}$.

(2) River leakage

The river leakage can be improved by building retaining dams at proper places. Shandong Province once issued a plan for enhancing karst groundwater recharge and optimizing groundwater exploitation in the study area. The plan states that four retaining dams (Table 5) should be constructed along the Xinxue River; once completed, the dams are expected to bolster river leakage to $22,000,23,000,6000$ and $17,000 \mathrm{~m}^{3} / \mathrm{d}$, respectively, in extremely dry years. In this way, the total recharge amount can reach $6.8 \times 10^{4} \mathrm{~m}^{3} / \mathrm{d}$.

Table 5. Recommended locations of the retaining dams

\begin{tabular}{c|cc}
\hline Preferential locations & XiaoDian country & DongYu country \\
\hline Increasing amount $\left(\mathbf{1 0}^{4} \mathbf{m}^{3} / \mathbf{d}\right)$ & 2.2 & 2.3 \\
\hline Preferential locations & HongLin country & BeiXin country \\
\hline Increasing amount $\left(\mathbf{1 0}^{4} \mathbf{m}^{3} / \mathbf{d}\right)$ & 0.6 & 1.7 \\
\hline
\end{tabular}




\section{GROUNDWATER LEVEL FORECAST}

\subsection{Forecast model}

Based on the previous forecast conditions, a forecast model was created on Visual MODFLOW (VMOD) and coupled with the established hydrogeological model to evaluate the maximum exploitation potential of groundwater in the study area, and determine the optimal exploitation plan for all groundwater source fields after implementing the above recharge enhancement measures. The total exploitation volume of all groundwater source fields was taken as the objective function, and the maximum exploitation depth of each field as the decision variable. The forecast model was established as follows:

The objective function can be expressed as

$\mathrm{Q}_{\text {total }}=\max \sum_{\mathrm{i}=1}^{11} \mathrm{Q}_{\mathrm{i}}$

where 11 is the total number of groundwater source fields; $Q_{i}$ is the exploitation volume of field $i$.

The constraints are listed below:

(1) Groundwater level

The 11 fields were considered as the control points of groundwater level. At each point, the groundwater level should never fall below the maximum exploitation depth:

$\mathrm{H}_{\mathrm{i}}^{\mathrm{t}} \geq \mathrm{H}_{\mathrm{i}}^{0} \quad \mathrm{i}=1,2, \cdots, 11 ; \quad t=1,2 \cdots, \mathrm{T}$

where $\mathrm{H}_{\mathrm{i}}^{\mathrm{t}}$ and $\mathrm{H}_{\mathrm{i}}^{0}$ are the groundwater level of field $\mathrm{i}$ at time $\mathrm{t}$ and the maximum exploitation depth of field $\mathrm{i}$, respectively; $\mathrm{T}$ is the total computing time.

(2) Exploitation volume

The exploitation volume $\mathrm{Q}_{\mathrm{i}}$ of field i must be lower than the allowable volume in Reference [28]:

$\mathrm{Q}_{\mathrm{i}} \leq \mathrm{Q}_{\mathrm{i}}^{0}$ where $Q_{i}$ is the exploitation volume of field $i ; Q_{i}^{0}$ is the allowable volume in Reference [28]

(3) Nonnegativity constraint

The decision variable must be positive:

$H_{i}^{t} \geq 0 \quad i=1,2, \cdots, 11 ; t=1,2 \cdots, T ; Q_{i} \geq 0 \quad i=1,2, \cdots, 11 ;$

where $\mathrm{H}_{\mathrm{i}}^{\mathrm{t}}$ is the groundwater level of field $\mathrm{i}$ at time $t ; \mathrm{Q}_{\mathrm{i}}$ is the exploitation volume of field $\mathrm{i} ; 11$ is the number of fields; $\mathrm{T}$ is the total computing time.

Then, the response matrix method was adopted to couple the forecast model with the previously established hydrogeological model using the GWM. Then, the coupled model was applied to obtain the maximum exploitation volume and the optimal exploitation plan for all groundwater source fields after implementing the above recharge enhancement measures. The MODFLOW data files required by the GWM were extracted [31], and the decision variable, objective function, constraints and optimization methods were imported to the GWM. The optimization results using historical and future precipitation series are recorded in Tables 6 7 and Figures 8 9.

\subsection{Forecast results}

(1) Optimization results using historical precipitation series

Under historical precipitation series, the maximum exploitation volume was $243,500 \mathrm{~m}^{3} / \mathrm{d}$; the optimal exploitation plan is given in Table 6; the duration curve on groundwater level of each field is presented in Figure 8. As shown in the figure, the groundwater level did not decrease continuously, and the maximum exploitation depths of all fields were shallower than the constraint. This means the karst groundwater in the study area supports the groundwater yield of $243,500 \mathrm{~m}^{3} / \mathrm{d}$

Table 6. Optimized exploitation volumes of groundwater source fields using historical precipitation series (unit: $\left.1 \times 10^{4} \mathrm{~m}^{3} / \mathrm{d}\right)$

\begin{tabular}{c|cccc}
\hline Well fields & SongTun & HouShiWan & NanZhuang & WeiZhuang \\
\hline Abstraction rate & 0.18 & 2.62 & 3.16 & 3.15 \\
\hline Well fields & XiShiLou & XuPo & LongShanTou & YangZhuang \\
\hline Abstraction rate & 4.98 & 2.2 & 1.0 & 2.35 \\
\hline Well fields & DongYu & DuanZhuang & WangHang & \\
\hline Abstraction rate & 1.3 & 1.51 & 1.9 & \\
\hline
\end{tabular}

The forecasted groundwater levels in the next 20 years are displayed in Figure 9. It can be seen that the cones of depression in the groundwater source fields were not merged when the groundwater was extracted at the maximum exploitation volume at all fields. Thus, there is a weak interaction between different fields.

Table 7 lists the groundwater balance of the groundwater source fields after continuously exploitation for 20 years at the optimized exploitation volumes. As shown in the table, the precipitation infiltration recharged $8.07745 \times 10^{7} \mathrm{~m}^{3} / \mathrm{a}$ of groundwater, taking up $65.67 \%$ of the total recharge. Thus, precipitation infiltration is still the leading recharge source of the study area. With the construction of retaining dams, the recharge of river leakage soared to $3.79235 \times 10^{7} \mathrm{~m}^{3} / \mathrm{a}$, accounting for $30.83 \%$ of the total recharge. The total recharge stood at $1.23005 \times 10^{8} \mathrm{~m}^{3} / \mathrm{a}$, slightly larger than the total discharge.

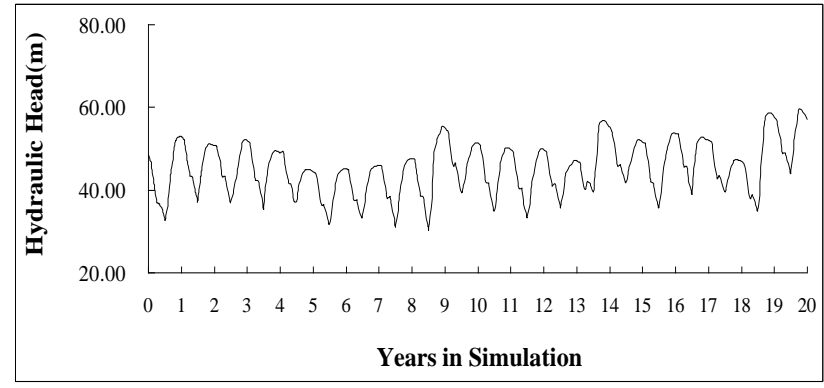

(a) YangZhuang Well field 


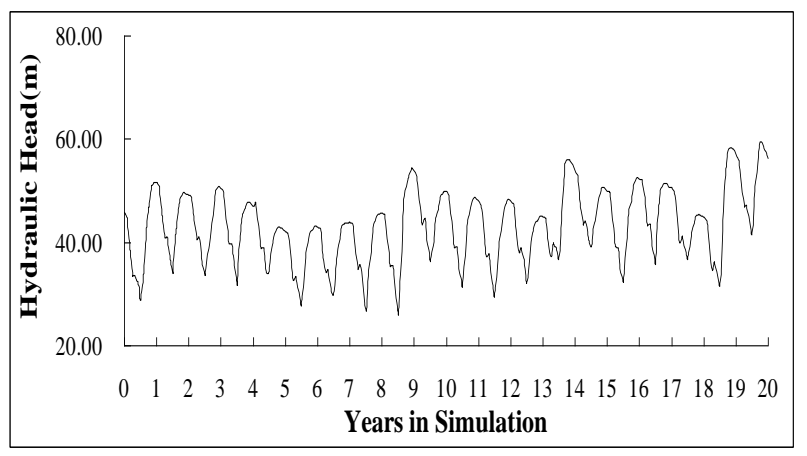

(b) XiShiLou Well field

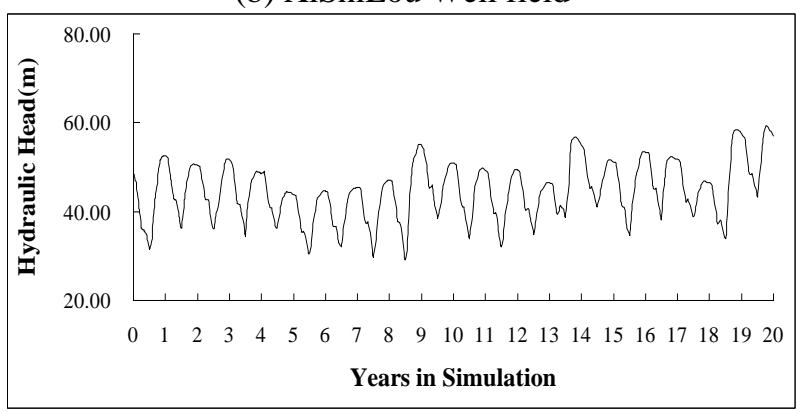

(c) WeiZhuang Well field

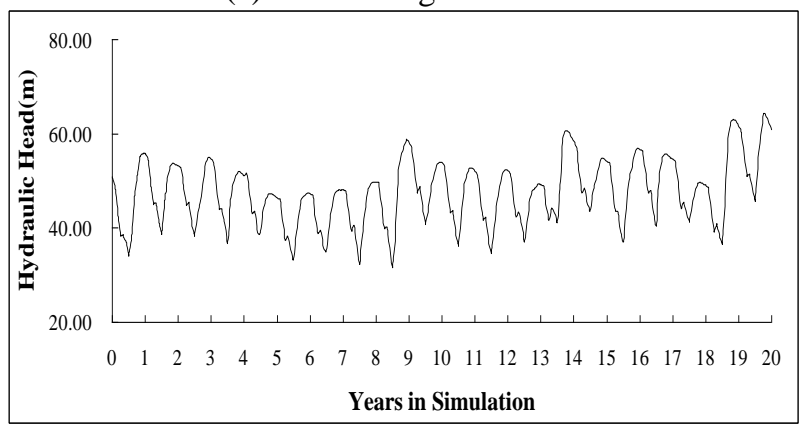

(d) HouShiWan Well field

Figure 8. Duration curve on groundwater level of each groundwater source field using historical precipitation series

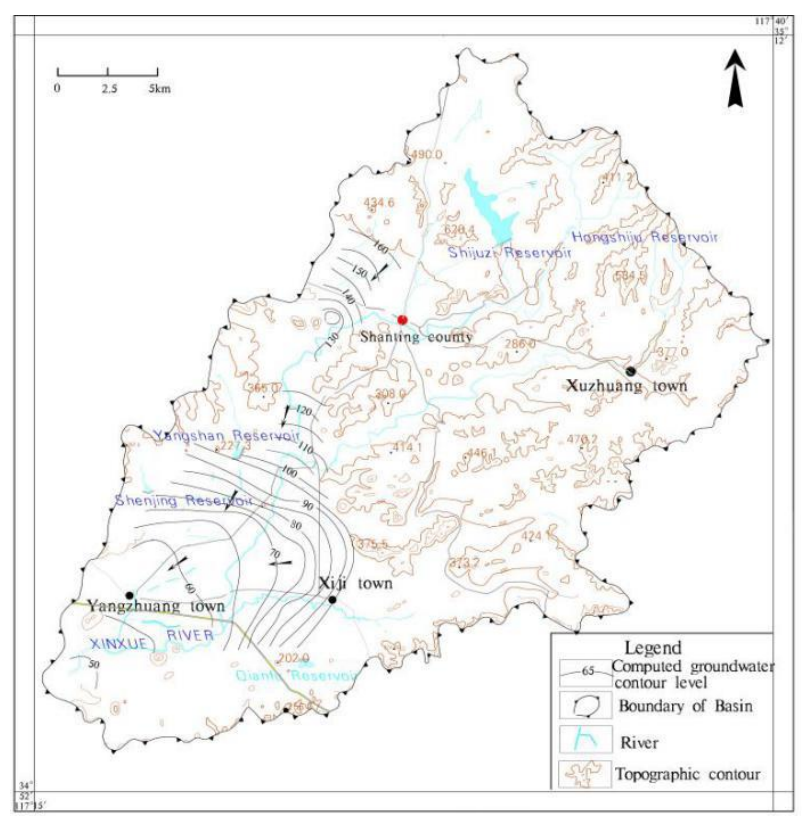

Figure 9. Forecasted groundwater levels in the next 20 years using historical precipitation series
Table 7. Groundwater balance of the groundwater source fields using historical precipitation series

\begin{tabular}{ccc}
\hline \multicolumn{1}{c}{ Water balance components } & Amount $\left(\mathbf{1 0}^{\mathbf{4}} \mathbf{m}^{\mathbf{3}} / \mathbf{y}\right.$ ear $)$ \\
\hline \multirow{3}{*}{ Inflow } & Recharge from precipitation & 8077.45 \\
\cline { 2 - 3 } & River Leakage & 3792.35 \\
\cline { 2 - 3 } & Irrigation return flow & 430.7 \\
\cline { 2 - 3 } & Total In & 12300.5 \\
\cline { 2 - 3 } Outflow & Public supply & 8887.75 \\
\cline { 2 - 3 } & Irrigation & 1752 \\
\cline { 2 - 3 } & Underflow & 229.95 \\
\cline { 2 - 3 } & Belfupplied domestic use & 492.75 \\
\cline { 2 - 3 } & Wei-zhuang Spring & 689.85 \\
\cline { 2 - 3 } & Total Out & 109.5 \\
\hline
\end{tabular}

(2) Optimization results using future precipitation series

Under future precipitation series, the maximum exploitation volume was $258,000 \mathrm{~m}^{3} / \mathrm{d}, 14,500 \mathrm{~m}^{3} / \mathrm{d}$ more than that under historical precipitation series. The increase is attributable to the different generation methods of the two series. The historical precipitation series was produced based on the worst water supply conditions, aiming to minimize the impact of human behaviours on groundwater level, while the future precipitation series was constructed considering both the past data and the current situation, which successfully eliminates the randomness of human behaviours. Hence, the exploitation volume calculated by the non-stationary future precipitation series is more rational than that by the historical precipitation series. In addition, the optimal exploitation plan is given in Table 8; the duration curve on groundwater level of each field is presented in Figure 10; the forecasted groundwater levels in the next 20 years are given in Figure 11.

Table 8. Optimized exploitation volumes of groundwater source fields using future precipitation series (unit: $1 \times 10^{4} \mathrm{~m}^{3} / \mathrm{d}$ )

\begin{tabular}{lcccc}
\hline \multicolumn{2}{l}{ Well fields } & SongTun HouShiWan & NanZhuang & WeiZhuang \\
\hline $\begin{array}{l}\text { Abstraction } \\
\text { rate }\end{array}$ & 0.27 & 2.75 & 3.26 & 3.19 \\
\hline $\begin{array}{l}\text { Well fields XiShiLou } \\
\text { Abstraction }\end{array}$ & XuPo & LongShanTou YangZhuang \\
rate & 5.16 & 2.37 & 1.21 & 2.49 \\
\hline $\begin{array}{l}\text { Well fields } \\
\text { DongYu }\end{array}$ & DuanZhuang & WangHang & \\
\hline $\begin{array}{l}\text { Abstraction } \\
\text { rate }\end{array}$ & 1.42 & 1.58 & 2.1 \\
\hline
\end{tabular}

The water budget of the entire aquifer obtained from the groundwater flow model is presented in table 9. The flow budget result indicates that the main recharge comes from precipitation, which represents about $65 \%$, followed by $32 \%$ xinxue river, and 3\% irrigation return flow. About the same amount of groundwater is extracted through pumping wells out of the system and only a very small part through springs or to rivers. The discrepancy is positive, indicating that outgoing 
groundwater from the basin is slightly lower than incoming groundwater. The figure 10 and figure 11 all show that the groundwater level never fall below the maximum exploitation depth at each control points of groundwater level,so the conclusion can be get that maximum exploitation volume was $258,000 \mathrm{~m}^{3} / \mathrm{d}$ is reliable under this scenario.

Table 9. Groundwater balance of the groundwater source fields using future precipitation series

\begin{tabular}{|c|c|c|}
\hline \multicolumn{2}{|c|}{ Water balance components } & Amount $\left(10^{4} \mathrm{~m}^{3} /\right.$ year $)$ \\
\hline \multirow{4}{*}{ Inflow } & Recharge from precipitation & 7978.9 \\
\hline & River Leakage & 3934.7 \\
\hline & Irrigation return flow & 430.7 \\
\hline & Total In & 12344.3 \\
\hline \multirow{8}{*}{ Outflow } & Public supply & 9417 \\
\hline & Irrigation & 1752 \\
\hline & Underflow & 175.2 \\
\hline & Self-supplied domestic use & 492.75 \\
\hline & Base flow & 372.3 \\
\hline & Wei-zhuang Spring & 76.65 \\
\hline & Total Out & 12285.9 \\
\hline & Inflow-Outflow & 58.4 \\
\hline \multirow[t]{2}{*}{ 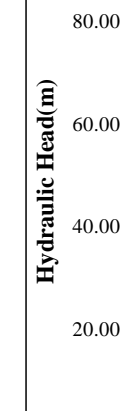 } & $\sqrt[W]{W} \sqrt{W}\}$ & $\sqrt[V]{ }$ \\
\hline & $\begin{array}{lllllllllll}0 & 1 & 2 & 3 & 4 & 5 & 6 & 7 & 8 & 9 & 10 \\
& & & & & & & & \text { Years in Sim } \\
\end{array}$ & 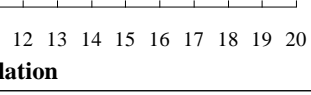 \\
\hline
\end{tabular}

(a) YangZhuang Well field

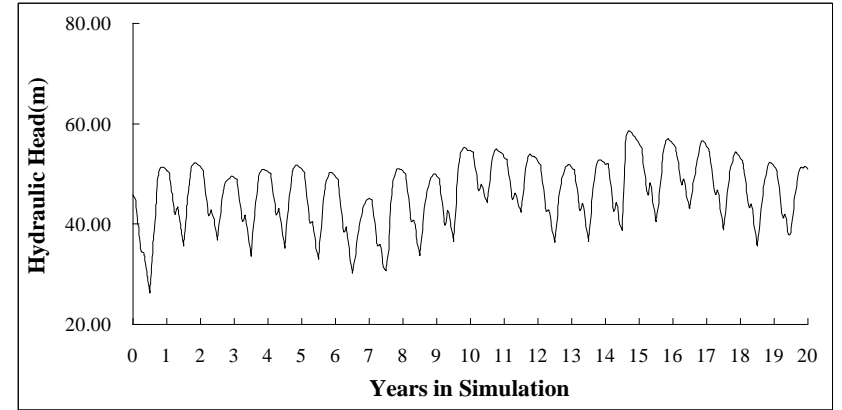

(b) XiShiLou Well field

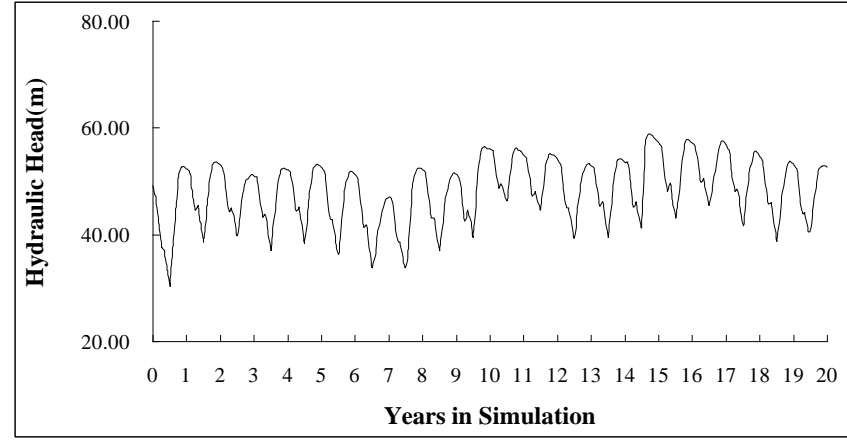

(c) WeiZhuang Well field

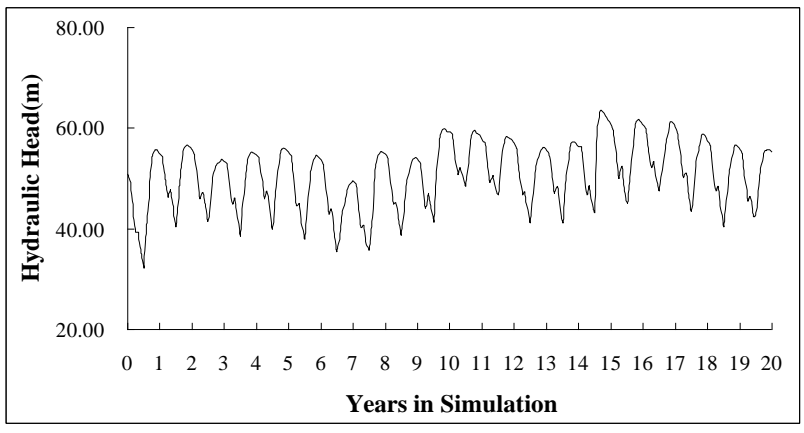

(d) HouShiWan Well field

Figure 10. Duration curve on groundwater level of each groundwater source field using future precipitation series

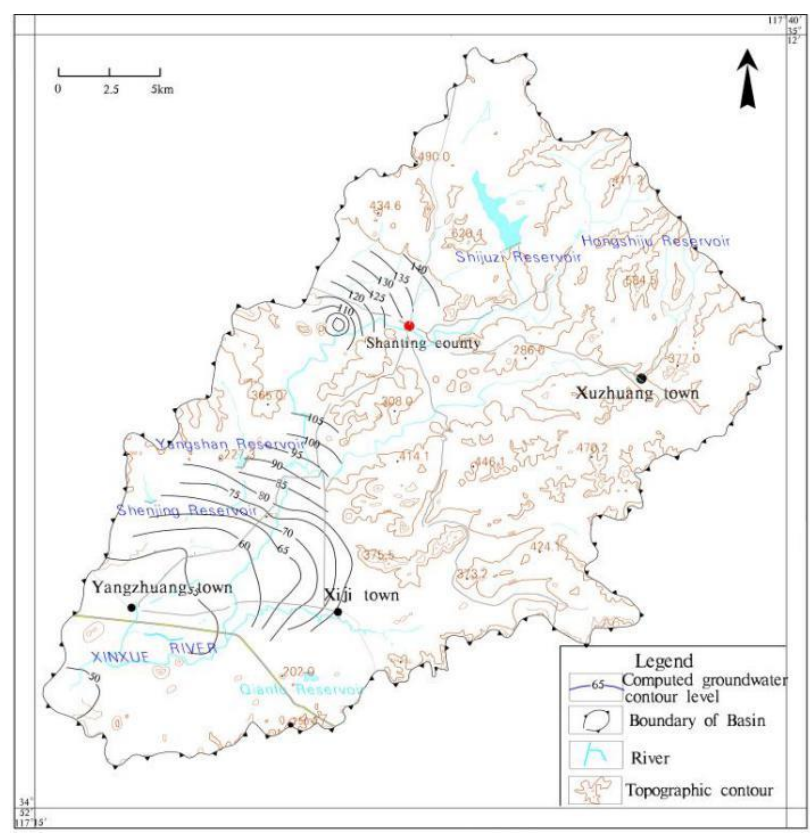

Figure 11. Forecasted groundwater levels in the next 20 years using future precipitation series

\section{Conclusions}

To determine the exploitation potential of groundwater and the optimal exploitation plan in karst areas, this paper selects Yangzhuang karst groundwater system as the study area. Then, a generalized hydrogeological model of groundwater flow was set up considering the hydrogeological and boundary conditions, and the governing equations were derived for karst groundwater simulation in the study area. After that, the study area was meshed into 31,152 rectangular grids by finite difference method. The established model was applied to simulate the groundwater levels in 25 observation wells, and proved to be feasible through the fitting of simulated results with the measured results.

Next, several forecast conditions and constraints were laid down, including but not limited to the precipitation calculated by historical series and future series (non-stationary) and the recharge enhancement measures like greening and retaining dam construction. Based on these conditions and constraints, a forecast model was created on Visual MODFLOW and coupled with the established hydrogeological model using the groundwater management (GWM) process to evaluate the maximum exploitation potential of groundwater in the study 
area, and determine the optimal exploitation plan for all groundwater source fields after implementing the above recharge enhancement measures. The main conclusions are as follows.

The exploitation volume calculated by the non-stationary future precipitation series outperforms that by the historical precipitation series in prediction accuracy. This is because historical precipitation series was produced based on the worst water supply conditions, aiming to minimize the impact of human behaviours on groundwater level, while the future precipitation series was constructed considering both the past data and the current situation, which successfully eliminates the randomness of human behaviours. Therefore, the allowable exploitation volume should be determined as $258,000 \mathrm{~m}^{3} / \mathrm{d}$.

By the most conservative estimate, the groundwater exploitation volume of the groundwater source fields can be maximized at $243,500 \mathrm{~m}^{3} / \mathrm{d}$. When the conditions get better, the feasibility of increasing the exploitation volume should be discussed according to the relationship between precipitation, exploitation and groundwater level. The research findings provide valuable references for sustainable exploitation and utilization of karst groundwater in the study area and similar regions.

\section{ACKNOWLEDGMENTS}

This research was partially supported by the program of Scientific Research Projects of the Higher University in Hebei (Nos.ZD2014023, QN2015061 and QN2017026), Scientific Research Initiation funds for PhD scholars (Nos.BQ2017011), China Postdoctoral Science Foundation(2018M631874) and Hebei province, science and technology plan projects (Nos.15273630).

\section{REFERENCES}

[1] Pulido BA. (1999). Karst hydrogeology and human activities: impacts, consequences and implications. In Drew D, Hötzl H. (eds), Balkema, Rotterdam, 225-234. https://doi.org/10.2113/gseegeosci.V.4.487

[2] Bakalowicz M. (2005). Karst groundwater: A challenge for new resources. Hydrogeol J. 13: 148-160. https://doi.org/10.1007/s10040-004-0402-9

[3] Ford D, Williams P.W. (2007). Karst hydrogeology and geomorphology. John Wiley and Sons, Chichester, Engl -and. https://doi.org/10.1002/9781118684986

[4] Parise M, Gunn J. (eds). (2007). Natural and anthropogenic hazards in karst areas: Recognition, Analysis and Mitigation. Geological Society London. https://doi.org/10.3986/ac.v37i1.528

[5] Dksy K, Imteaz MA, Arulrajah A. (2017). Development of groundwater vulnerability zones in a data-scarce eogenetic karst area using Head-Guided Zonation and particle-tracking simulation methods. Water Research 122: 17-26. https://doi.org/10.1016/j.watres.2017.05.056

[6] Taheri K. (2005). Sinkhole hazards in Karst terrains (with emphasis on Sinkholes of Hamedan). West Regional Water Authority of Iran, Kermanshah (in Farsi).

[7] Bonacci O, Pipan T, Culver DC. (2009). A framework for karst ecohydrology. Environ Geol 56: 891-900. https://doi.org/10.1007/s00254-008-1189-0
[8] Gutie'rrez F. (2010). Hazards associated with karst. In: Alca 'ntara I,Goudie A (eds) Geomorphological hazards and disaster preven-tion. Cambridge University Press, Cambridge, $161-175$. https://doi.org/10.1017/cbo9780511807527.013

[9] Parise M. (2010). Hazards in karst. In: Bonacci O (ed) Proceedings of international interdisciplinary scientific conference on"sustain-ability of the karst environment. Dinaric karst and other karst regions", Plitvice Lakes (Croatia), 23-26. Sep 2009, IHP-UNESCO, series on groundwater 2, 155-162.

[10] Parise M. (2015). Karst geo-hazards: causal factors and management issues. Acta Carsologica 44(3): 401-414. https://doi.org/10.3986/ac.v44i3.1891

[11] Karimi H, Taheri K. (2010). Hazards and mechanism of sinkholes on Kaboudar Ahang and Famenin plains of Hamadan. Iran. Nat Hazards 55: 481-499. https://doi.org/10.1007/s11069-010-9541-6

[12] Taheri K, Gutie 'rrez F, Mohseni H, Raeisi E, Taheri M. (2015a). Sinkhole susceptibility mapping using the analytical hierarchy process (AHP) and magnitudefrequency relationships: A case study in Hamadan province, Iran. Geomorphology 234: 64-79. https://doi.org/10.1016/j.geomorph.2015.01.005

[13] Taheri K, Taheri M, Parise M. (2015b). Unprotected karst resources in western Iran: The environmental impacts of intensive agricultural pumping on the covered karstic aquifer, a case in Kermanshah province. Geophys Res Abstr 17: 1640.

[14] Teutsch G. (1993). An Extended Double-Porosity Concept as a Practical Modeling Approach for a Karstified Terraine. Hydrogeological Processes in Karst Terraines. Proceedings of the Antalya Symposium and Field Seminar, International Association of Hydrological Sciences, Wallingford, October 1990, 281-292.

[15] Scanlon BR, Mace RE, Barret ME, Smith B. (2003). Can We Simulate Regional Groundwater Flow in a Karst System Using Equivalent Porous Media Models Case Study, Barton Springs Edwards Aquifer, USA. Journal of Hydrology 276: 137-158. https://doi.org/10.1016/s00221694(03)00064-7

[16] Pankow JF, Johnson RL, Hewetson JP, Cherry JA. (1986). An evaluation of contaminant migration patterns at two waste disposal sites on fractured porous media in terms of the equivalent porous medium (EPM) model. Journal of Contaminant Hydrology 1: 65-76. https://doi.org/10.1016/0169-7722(86)90007-0

[17] Neuman SP. (1987). Stochastic Continuum Representation of Fractured Rock Permeability as an Alternative to the REV and Fracture Network Concepts. In: Custodio E., Gurgui A, Lobo-Ferreira J.P (eds) NATO Advanced Workshop on Advances in Analytical and Numerical Groundwater Flow and Quality Modelling, NATO ASI Series, Series C: Mathematical and Physical Sciences, 224: 331-362. https://doi.org/10.1007/978-94-009-2889-3 19

[18] Huntoon PW. (1994). Is It Appropriate to Apply Porous Media Groundwater Circulation Models to Karstic Aquifers In: El-Kadi A.I (eds) Groundwater Models for Resources Analysis and Management, CRC/Lewis Publishers, Boca Raton, 339-358.

[19] Quinn TM, Vacher HL. (2004). Geology and hydrogeology of carbonate islands, Elsevier Science, 
Amsterdam.

4571(04)x8019-5

[20] Martínez-Santos P, Andreu JM. (2010). Lumped and distributed approaches to model natural recharge in semiarid karst aquifers. Journal of Hydrology 388(3-4): 389-398. https://doi.org/10.1016/j.jhydrol.2010.05.018

[21] Abusaada M, Sauter M. (2013). Studying the Flow Dynamics of a Karst Aquifer System with an Equivalent Porous Medium Model. Groundwater 51(4): 641-650. https://doi.org/10.1111/j.1745-6584.2012.01003.x

[22] Mayaud C, Wagner T, Benischke R, Birk S. (2014). Single event time series analysis in a binary karst catchment evaluated using a groundwater model (Lurbach system, Austria). Journal of Hydrology 511: 628-639. https://doi.org/10.1016/j.jhydrol.2014.02.024

[23] Waterloo Hydrogeology. (2006). Visual MODFLOWv. 4.2 user's manual: For professional application in threedimensional groundwater flow and contaminant transport modeling. Waterloo $\mathrm{ON}, 632 \mathrm{pp}$.

[24] Ahlfeld DP, Barlow PM, Mulligan AE. (2005). GWMA ground-water management process for the U.S. Geolo gical Survey modular groundwater model (MODFLOW -2000): U.S. Geological Survey Open-File Report 2005 1072,124

[25] Li CM, Kang FX. (2001). Research on karst water resources and augmenting recharge sources and augmenting permissible yield for the Yangzhuang basin in Shangdong province. South-to-North Water Transfers and Water Science \& Technology 10: 103.
[26] Bear J. (1977). On the aquifer integrated balance equations. Adv Water Res 1:15-23. https://doi.org/10.1016/0309-1708(80)90058-5

[27] Qiu SW, Liang XJ, Xiao CL, Huang H, Fang Z. (2015). Numerical Simulation of Groundwater Flow in a River Valley Basin in Jilin Urban Area, China. Water (7): 5769. https://doi.org/10.3390/w7105768

[28] Chen SL, Yang W, Huo ZL, Huang GH. (2016). Ground -water simulation for efficient water resources management in Zhangye Oasis. Northwest China.Environmental Earth Sciences 75(8): 647. https://doi.org/10.1007/s12 665-016-5458-z

[29] Gebreyohannes T, Smedt FD, Walraevens K, Gebresilas sie S, Hussien A, Hagos M, Amare K, Deckers J, Gebre hiwot K. (2017). Regional groundwater flow modeling o $\mathrm{f}$ the geba basin, northern ethiopia. Hydrogeology Journ al. 25(3): 639-655. https://doi.org/10.1007/s10040-016$1522-8$

[30] Wu JF, Zhu XY, Qian JZ. (2000). A time series model with finite element method for rational exploration of fracture karst water resources in Xuzhou city. Geological Journal of China Universities 6(3): 470.

[31] McDonald MG, Harbaugh AW. (1988). A modular threedimensional finite-difference groundwater flow model. US Geological survey techniques of water-resources investigations, book 6, Chap. A1, US Geological Survey, Open-File report 83-875. 